\title{
Perceived relevance of an introductory information systems course to prospective business students
}

\author{
Irene Govender, Elvira Naidoo \\ Discipline of Information Systems and Technology, University of KwaZulu-Natal, South Africa
}

\begin{abstract}
The study is designed to examine students' perceptions of the introductory Information Systems (IS) course. It was an exploratory study in which 67 students participated. A quantitative approach was followed making use of questionnaires for the collection of data. Using the theory of reasoned action as a framework, the study explores the factors that influence non-IS major students' perceived relevance of the IS introductory course. The analysis of collected data included descriptive and inferential statistics. Using multiple regression analysis, the results suggest that overall, the independent variables, relevance of the content, previous IT knowledge, relevance for professional practice, IT preference in courses and peers' influence may account for $72 \%$ of the explanatory power for the dependent variable, perceived relevance of the IS course. In addition, the results have shown some strong predictors (IT preference and peers' influence) that influence students' perceived relevance of the IS course. Practical work was found to be a strong mediating variable toward positive perceptions of IS. The results of this study suggest that students do indeed perceive the introductory IS course to be relevant and match their professional needs, but more practical work would enhance their learning. Implications for theory and practice are discussed as a result of the behavioural intention to perceive the IS course to be relevant and eventually to recruit more IS students.
\end{abstract}

KEYWORDS: students' perceptions, information systems, non-majors, curriculum, perceived relevance, information technology, BCom

CATEGORIES: H.2.1

\section{INTRODUCTION}

The increasing prominence of digital technology in organizations and society on the one hand, and the continued decline in enrolment in IS programs at many universities on the other, necessitates the re-consideration of the value of IS courses, specifically the introductory courses. One of the key themes that has emerged from recent research is the recruitment of more students to the field of IS [1. Downey, McGaughey and Roach 2] determined that one of the main reasons students are not choosing to major in IS is because they are unfamiliar with either the content or the concept of IS. This unfamiliarity with IS signifies the importance of the introductory IS course as a chance not only to promote the relevance of IS in an organization 3 but also to instil the importance of IS in an organization for efficiency and increased productivity.

The main aim of any discipline of IS should be clear; that is to investigate and teach how organizations, business or otherwise, can make use of computers and information technology to further their business goals. To this end the introductory course in IS should provide all students with knowledge of the functions and value

Email: Irene Govender govenderi4@ukzn.ac.za, Elvira Naidoo 206506648@stu.ukzn.ac.za of information systems and resources in organizations.

At the institution in which the study was carried out, all BCom students take a compulsory introductory course in IS, even if they do not major in IS. It has been observed that many students fail to pass the course on the first attempt. Anecdotal evidence suggests that the content of the introductory course may not have particular relevance for students who pursue majors other than IS. We wanted to determine the relevance of the introductory course in IS for all business students. One of the initial steps towards this goal was to determine students' views of the course.The purpose of this study was therefore to investigate non-major IS students' perceived relevance of the introductory IS course, 'Information Systems and Technology for Business' (ISTN101), in order to develop strategies to interest students who might otherwise choose other business majors.

The study was guided by the following research questions:

1. What are non-IS major students' opinions and reflections about the course?

2. Do important referents influence students' choice of or enhance their awareness of the importance of IS in business practices and education? 
3. Does the introductory IS course meet the perceived professional needs of prospective BCom graduates?

The remainder of the paper is organized as follows: Section 2 examines some of the relevant literature. Section 3 describes the theoretical framework for the study. Section 4 explains the research design, expanding on the data and methodology. Section 5 discusses the findings of the analysis. Section 6 concludes, highlighting possibilities for future research.

\section{LITERATURE REVIEW}

Being able to develop students to meet the needs of commerce and industry is very important to staff who develop the IS curriculum as well as understanding how it links with the rest of the courses in the Bachelor of Commerce (BCom) degree.

The wide use of technologies such as computer networking, mobile computing, online social networking and the Internet in general by individuals and organizations is phenomenal. It is therefore encouraged and even expected that these individuals, particularly the BCom graduates whose main area of expertise may not be in information technology understand and apply these technologies effectively in IS [4.

Any IS lecturer will argue, and rightfully so, that the first year IS modules must provide a foundation of necessary IS skills: proficiency in getting your computer to do what you want it to do; understanding of what your computer can do; and understanding of how it does it. For any prospective BCom graduate, whether the major is Accounting, Finance or Management, IS skills are essential. Zhang's [5] study affirms the importance of IS skills. In addition, Zhang posits that in order to change negative perceptions of IS, the key is to emphasize how IS is used to support business when presenting it in the introductory course. For the same reason, Bullen, Abraham, Gallagher, Simon and Zwieg [6] believe that the value of "teaching information systems in a cross-functional context" is that it stresses the supportive part IS can play in organizational structures and processes. George, Valacich and Valor [7] highlight the importance of relevance in the IS curriculum. They further stress the importance of being able to provide students with insight about IS - e.g., that IS is about technology as a means for attaining business goals more effectively and efficiently. Freedman and Wyner [1] concur with what Bullen et al. 6 claim, and is therefore worth further investigation as the IS sector seeks to create a compelling lecture experience for all business students and potential IS major students.

Granger, Dick, Luftman, Van Slyke and Watson 8 suggest some ways of making the introductory course of IS more inviting: making content more relevant to students, focussing on how technology supports the business, and avoiding the teaching of basic computer concepts that are familiar to tech-savvy students [7]. Firth, Lawrence and Looney 9 suggest a 12 -step program for enhancing the effectiveness of the introduc- tory IS course, specifically as it relates to encouraging enrolment in the IS major.

Teaching a first course in IS or in any computing area can be a challenge, especially if the students in the same lecture have different desires or purposes for enrolling in the course: e.g., non-majors of IS, beginning computer science majors, or employed adults in IS fields seeking to increase or polish their skills in some areas for their current job. Moreover, some university students have never come into contact with a computer before while others are much more technologically advanced and may find the course irrelevant and a waste of time. The difference in student backgrounds and previous computing experience is very likely to influence their perspectives of the introductory course.

Kaminski, Switzer and Gloeckner [10] stress the importance of organizations incorporating technology in their everyday practices in order to achieve the expected results. It is prudent that schools or a discipline of IS should maximize the impact of technology as well in their curriculum. Many universities have made IS skills a graduation requirement [10. Karminski et al. argue that being adept with information technology enables one to express oneself creatively, recreate knowledge, and synthesize new information. This enablement develops the process of lifelong learningequipping individuals to apply their knowledge and skills to adapt to change to be more effective in their work and personal lives. We believe that skills acquisition courses such as Information Systems (IS) at a first year level of tertiary education, provide non-major IS students with the fundamentals in IS which should lead to practical outcomes that are useful to them now and in their future professions (be it IT-related or otherwise). Despite the rapidly developing nature of Information Technology (IT), which does impact IS, the curriculum should have some endurance. There is no doubt that the dynamic nature of the subject poses additional challenges to IT educators [11.

While there is agreement regarding the application and importance of IS in business degrees, there were mounting fears about their limited worth to non-major IS courses [12. A growing body of research shows that IS is one of the most critical components for effective business processes and productivity [13.

It has been demonstrated in previous research that students who received some form of computer/IS training or education are better equipped to work selfassuredly with computers and related tasks than students who received no preparation at all 14. The above concerns beg the question: is the current introductory IS programme preparing prospective BCom graduates to successfully use IS skills in their work? Bullen et al. 6 found that IS curriculum changes were not abreast with the needs of prospective employers and managers in the marketplace.

Ultimately, every student hopes that every module passed in their degree would enable them to better perform in the business world. It is difficult for any undergraduate student to have the capacity to understand the relevance of a module until the individual 
has had the chance to see its practical use in business therefore only the perceptions are considered, which should help to enhance the course and possibly improve enrolment. Gorgone, Davis, Valacich, Topi and Longenecker [4] assert that it is necessary to look at what the market demands because the primary focus of a university should be to provide a general, theoretical type of education that enables students to become lifelong learners, and thus better equipped to adapt to changes.

However, anecdotal evidence and the reviewed literature suggest that several gaps exist between student perceptions of the skills they need and the actual IT skills employers require 15. Janicki, Lenox, Logan and Woratschek 16 recognize the importance of such courses not becoming training' courses, but rather ones that will equip students with the necessary skills to learn new technologies as they evolve.

Linking what IS practitioners expect of graduates and what graduates have learned will require a renewed look at the IS curriculum. More importantly, it has been noted that showing how theory can be applied in practice goes a long way in motivating students to learn and establish relevance of the curriculum [7]. In trying to answer the research questions posed earlier, we delineated the questions further into the following specific objectives:

- To determine the value of each of the sub topics in ISTN101 as perceived by students.

- To determine the influence of previous computer exposure of students on their perceptions of ISTN101's usefulness?

- Do students perceive ISTN101 to be useful in preparing them for the professional world?

- Does their IT preference in courses influence their perceptions of the relevance of ISTN101?

- Do peers have an influence on student perceptions of ISTN101 value?

- To determine the relative impact of each of the above objectives

- To determine the usefulness of the different modes of delivery of ISTN101 content

\section{THEORETICAL FRAMEWORK}

The purpose of this study was to assess the perceived relevance of introductory IS courses that are offered to non-major IS students in the BCom degree programme. The development of the introductory IS course in the BCom graduate programme to meet current and future IS needs is determined in the light of a survey of non-major IS students; substantiated by the collection of data on the contents of the introductory IS course. We believe that by determining students' perceptions ('perceived relevance') of the introductory course, and thereby using these perceptions to modify the course so that it can be made more desirable to students, it would influence student enrolment in IS courses. Furthermore, statistics at the university show that despite increasing student registrations for business degrees, a much lower percentage of students are choosing to major in IS, which exacerbates the situation described in [9]. This concern relates directly to the perceived relevance of IS to non-major students compelled to take the introductory IS course.

It is in this light that we investigate why these differences exist, and attempt to improve the situation. In the light of the forgoing discussion, we believed that students' perception of the different areas of study in the introductory course is an important predictor of the desirability of the course. Prior experiences with IT or related aspects, and students' preference for courses that make use of IT usually have some influence as well. A fourth aspect that has shown to have some influence in students' perceived relevance of the IS course is their perceived relevance for professional practice or career. These factors would contribute to their attitude towards IS as an integral aspect of their degree if not as a potential major in their degree. In addition, it is believed that people who are respected, honoured or well-regarded by students may play a role in the choice of IS as a major or enhance the awareness of IS importance in Business [17. Such people may be their teachers, family and peers.

The theory of reasoned action (TRA) proposed that an individuals' behavior is determined by his/her intention to perform the behavior, and this intention is influenced jointly by his/her attitude toward performing the behavior as well as the perceived social influence of people who are important to him/her (subjective norm). Based on the theory of reasoned action (TRA), two key constructs, attitude and subjective norm are used to analyse student intention (behavior). Attitude and subjective norm are direct determinants of usage intention, behavior and its associated relevance 18 . TRA has been used to predict a wide range of behaviours. Davis et al. [19] applied the TRA to individual acceptance of technology and found that the variance explained was consistent with studies that used TRA in the context of other behaviours. The two constructs attitude and subjective norm were further delineated into the independent variables:

- 'perceived value of content',

- 'previous IT knowledge',

- 'IT preference in courses taken',

- 'perceived relevance for professional practice', and

- 'peer influence'.

The mediating variable, 'perceived relevance of introductory IS course' helps us to conceptualize and understand how the independent variables bring about the decision to major in IS. Perceived relevance of introductory IS course is a function of attitude and subjective norm. Furthermore, practical work enhanced the behavioural intention to choose IS, acting as a moderating variable.

A diagrammatic representation of the constructs or variables that influence students' perceptions of the relevance of the IS curriculum and the conceptual relationship between the key variables of the model are reflected in Figure 1 . 


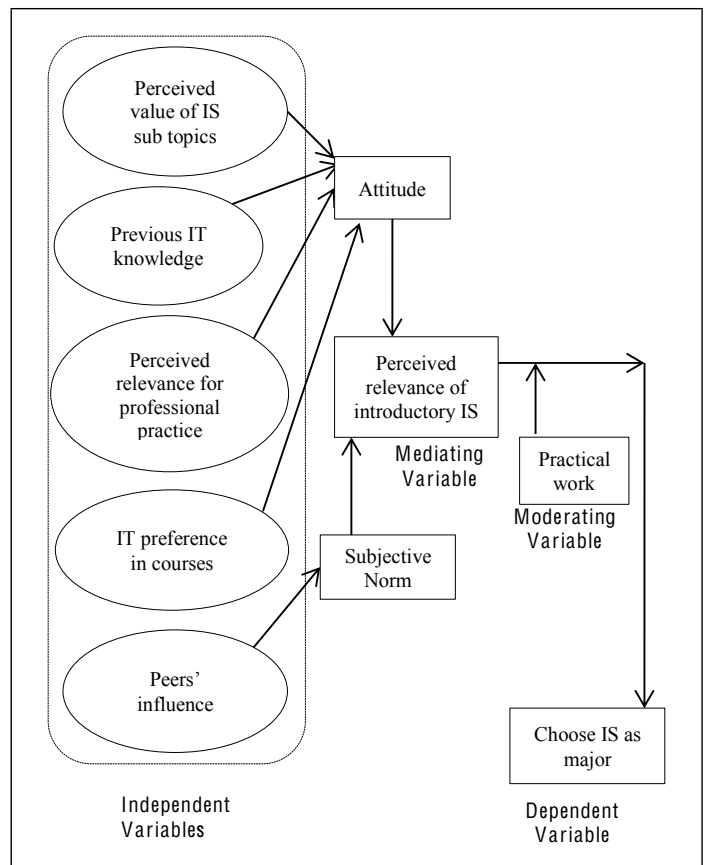

Figure 1: Framework for this study based on Theory of Reasoned Action (TRA)

\section{METHODOLOGY}

The quantitative approach was adopted in this study so that the researcher remains objective and the results are objectively summarized and analyzed. The quantitative approach allows us to quantify the problem and understand how widespread it is in a larger population 20. In other words, researching a small group can give a reliable indication of the views of a larger population. Due to the highly specific nature of this study, the research targeted undergraduate Bachelor of Commerce non-major IS students who enrolled for the mandatory introductory course in IS, ISTN101.

\subsection{Description of course}

The course comprised topics including:

- Information Systems in organizations,

- hardware and software,

- operating system features of Windows,

- business information systems,

- use of a word processor to work more effectively,

- use of spreadsheets for analysis, statistics and decision making,

- networks (connecting a computer to a network),

- business intelligence and database systems,

- pervasive computing, and

- security.

The course was delivered in the form of lectures, tutorials and practical work. Computer literacy was embedded in the introductory IS course to cater for students who had not done any computer related course at schools. Additional tutorials and practical work provided some kind of scaffolding for these students.

\subsection{Research instrument}

A questionnaire was used as a means for data collection. The questionnaire was divided into three sections (Sections A, B, and C). Section A required respondents to provide demographical information. This was used to determine any relationships between demographical variables and other variables outlined in the questionnaire. Section B gathered information regarding respondents' levels of IS skills and computer use. Section C elicited information regarding students' views of the different topics within the introductory IS curriculum, as it had a bearing on the main issue at hand which is the student perceptions on the relevance of the introductory course (ISTN101). The questionnaires were distributed to the respondents personally.

\subsection{Sampling}

The population consisted of undergraduate Bachelor of Commerce non-major IS students who enrolled for the introductory IS course. A sample size of 100 was hoped to be achieved but only 67 were obtained due to various limitations such as time and budget constraints. Non-probability sampling was utilized as it was easy to administer, less costly and less time consuming. Therefore, the generalizability of the findings was limited to the characteristics of the subjects in the sample and may have led to it being biased.

In addition to the sampling being non-probable, it was purposive as well. According to Sekaran and Bougie [21, when the participants are subjectively selected with a specific purpose in mind (as was done in this study) it is then referred to as purposive sampling. In effect, the purpose reflects the particular qualities of the students chosen and their relevance to the topic of investigation. Therefore, only the non-IS major students who have done ISTN101 can provide relevance and meaning to this investigation.

\subsection{Analysis}

The data was analyzed using SPSS (Statistical Package for the Social Sciences), which is a computer application that provides statistical analysis of data. Statistical analyses ranging from basic descriptive statistics, such as means and frequencies, to advanced inferential statistics, such as multiple regression analyses of variance was carried out.

\section{FINDINGS}

This section presents the results and analysis of the empirical data collected from the questionnaires.

\subsection{Reliability testing}

To test the goodness of data, the reliability of all variables was established by testing for both consistency and stability. In Table 1. Cronbach's alpha was computed to be 0.758 (>0.5) indicating a high and acceptable internal consistency reliability of the data items. 


\subsection{Demographics}

Both genders were evenly represented with males and females occupying $54 \%$ and $46 \%$ of the sample respectively. All races were adequately represented by the respondents with $64 \%$ Indian, $28 \%$ Black, $5 \%$ Coloured and $3 \%$ white. These demographics had no bearing on the perceived relevance of IS and therefore were not considered further in the study.

Students were asked to rate their level of agreement with respect to the relevance and helpfulness of the topics on a scale of 1 to 5 . Point values for the responses were assigned as follows:

1. 'strongly disagree',

2. 'disagree',

3. 'not sure',

4. 'agree',

5. 'strongly agree'.

Means and standard deviations were calculated for each feature.

Table 1 indicates the means and standard deviations with regard to their perceived effectiveness of the content of introductory IS course.

The analysis showed that in general most topics covered in the introductory course of ISTN101 assisted students in their studies in other majors. An overwhelming percentage of students agreed that ISTN101 has helped them become more familiar with, and better understand the use of, the sub-topics. The overall high ratings of some of the sub-topics, such as 'Windows operating systems' and 'word-processing', speak to the importance of the basic computer skills for creating and manipulating documents required in any organization. However, a large percentage of students were not sure whether they found networks $(46.3 \%)$ and databases $(35.8 \%)$ useful in their work. This uncertainty may be attributed to them not understanding the work or possibly more time was needed to develop their interest in the topic.

Students' self-reported proficiency levels of IT are represented in Table 2

$P<0.05$ so the neutral option (with highest absolute residual $=9.6$ ) was selected significantly more often than others. This suggests that students were not sure of their competence of their previous knowledge of IT. In determining students' perceptions of the relevance of IS in their future professional careers, we determined the means and standard deviations of those items related to professional practice, using the scale of 1 to 5 for the levels of agreement. Students rated their level of agreement to the items in Table 3 in response to the statement "ISTN101 will benefit you in your future profession by...".

The high means for each of the items clearly indicates that the majority of the respondents agreed that ISTN101 will benefit them in their future profession in the aforementioned ways. We can therefore deduce that students perceive that ISTN101 will contribute to their professional preparation.

Table 4 shows the means and standard deviations of students' preferences to courses that involve the use of IT; whether they prefer taking courses with 'no', 'limited', 'moderate', 'extensive' or 'exclusive' levels of IT was captured. The general mean $(M=3.19)$ of students preferring to take courses with IT was significant.

The next independent variable we examined was the perceived influence of peers and instructors on the modes of instruction and learning.

In Table 5 it is evident that in general, peers and lecturers do have a positive influence on practical, tutorial and lecture attendances, as well as their learning and understanding of the module. It is noteworthy to mention the wide divide between the positive and negative influence of peers with regard to lecture attendance. However, it is not all bad, as the positive influence is noticeable in the other modes of instruction. What is strikingly clear in Table 5 is the high percentage of positive influence regarding the practical work. This serves to emphasize the need for 'hands-on' and active learning, and the importance it plays in overall learning.

Furthermore, we wanted to determine the degree to which each of the independent variables or factors could predict the perceived relevance of the introductory IS course offered to prospective business students and hence to influence their intention to switch to IS majors.

Using multiple regression analysis, the first step in the analysis was to enter all independent (predictor) variables for the total sample into a regression equation to determine the relative importance of each variable. The independent variables are positively correlated with the dependent variable - the perceptions of relevance of the content, previous IT knowledge, perceived value for professional practice, IT preference and peers' influence, are positively associated with the perceived relevance of IS for non-major students. The significant independent variables are shown in Table 6 , the dependent variable is 'perceived relevance of introductory IS course'.

The regression estimate can be read from the standardized coefficients (SC) or $\beta$ value. If the coefficients could be zero for any of the predictors then these variables might not matter because it is a statistical proof. The beta $(\beta)$ value is a measure of how strong the predictor variable influences the dependent variable. The higher the $\beta$ value the greater the impact of the predictor variable on the independent variable. We look at the $p$-values ('Sig.'). If the Sig. values are very small then we can reject the null hypothesis for each of the individual predictors. The perceived importance of the content has a $p$-value that is very high and a corresponding $t$-value that is less than 1 . This means that this variable can be removed from the analysis. In other words, the perceived importance of the content might not matter in influencing the perceived relevance of the IS course as a mandatory course for all BCom students.

From the five independent (predictor) variables considered together, it appears only that 'IT preference' and 'peers' influence' matter in contributing to the overall positive perception of the introductory 
Table 1: Rated perceived relevance of topics in IS

\begin{tabular}{|c|c|c|c|}
\hline Topics in IS & Count & Mean & Std Deviation \\
\hline Information systems in organisations & 67 & 3.80 & 0.67 \\
\hline Hardware and software & 67 & 3.92 & 0.65 \\
\hline Operating system features of Windows & 67 & 4.04 & 0.722 \\
\hline Use of a word processor to work more effectively & 67 & 4.08 & 0.69 \\
\hline Use of spreadsheets for analysis and statistics & 67 & 3.79 & 0.86 \\
\hline Networks (connecting computers in networks) & 67 & 3.37 & 0.85 \\
\hline Database system to set up and retrieve useful information & 67 & 3.46 & 0.94 \\
\hline
\end{tabular}

Table 2: Frequencies: previous computing experience / IS skills

\begin{tabular}{|l|c|c|c|c|}
\hline \multicolumn{6}{|c|}{ When I entered university, I was adequately prepared to use IT as needed in my courses } \\
\hline & Category & Observed N & Expected N & Residual \\
\hline 1 & Strongly agree & 6 & 13.4 & -7.4 \\
2 & Agree & 18 & 13.4 & 4.6 \\
3 & Neutral & 23 & 13.4 & 9.6 \\
4 & Disagree & 13 & 13.4 & -0.4 \\
5 & Strongly disagree & 7 & 13.4 & -6.4 \\
\hline Total & & 67 & & \\
\hline
\end{tabular}

Table 3: Students' perceptions of ISTN101 professional preparation of graduates

\begin{tabular}{|c|c|c|c|}
\hline & Count & Mean & Std Deviation \\
\hline Preparing you for the workplace & 67 & 3.597015 & 0.970156 \\
\hline Making strategic decisions in the workplace & 67 & 3.626866 & 0.918428 \\
\hline Improving job performance & 67 & 3.985075 & 0.639425 \\
\hline Increasing productivity in the workplace & 67 & 3.970149 & 0.650644 \\
\hline Understanding IT practices in the workplace more clearly & 67 & 3.940299 & 0.756399 \\
\hline Improving the quality of work & 67 & 4.029581 & 0.797157 \\
\hline
\end{tabular}

Table 4: Students' IT preference in courses

\begin{tabular}{|l|c|c|c|}
\hline IT preference & Count & Mean & Std Deviation \\
\hline Prefer courses that involve more IT & 67 & 2.791045 & 0.807865 \\
I get more actively involved in courses that use information technology & 67 & 3.119403 & 1.022806 \\
The use of IT in my courses improves my learning & 67 & 3.41791 & 1.032051 \\
IT makes doing my course activities more convenient & 67 & 3.432836 & 0.988171 \\
\hline
\end{tabular}

Table 5: Influence of peers and lecturers on learning and attendance

\begin{tabular}{|l|c|c|c|}
\hline Peer influence & Positively & Negatively & No influence \\
\hline Lectures & 52.2 & 46.3 & 1.5 \\
Tutorials & 71.6 & 22.4 & 6 \\
Practicals & 83.6 & 13.4 & 3 \\
Learning & 80.6 & 14.9 & 1.5 \\
\hline Lecturer influence & & & \\
\hline Lectures & 64.2 & 32.8 & 3 \\
Tutorials & 71.6 & 22.4 & 6 \\
Practicals & 83.6 & 11.9 & 4.5 \\
Learning & 70.1 & 22.4 & 7.5 \\
\hline
\end{tabular}

Table 6: Regression analysis-coefficients of the predictor variables

\begin{tabular}{|rr|c|c|c|c|c|}
\hline Model & & Unstandardized coefficients & Standardized coefficients & t & Sig. \\
\hline & & B & Std. error & $\beta$ & & \\
\hline & (Constant) & -1.221 & 0.232 & & -5.252 & .000 \\
\multirow{4}{*}{1} & Perceived_value_of_topics & -0.080 & 0.134 & -0.118 & -0.596 & 0.553 \\
& Previous_IT_knowledge & -0.098 & 0.051 & -0.233 & -1.924 & 0.059 \\
& Professional_practice & 0.207 & 0.176 & 0.303 & 1.176 & 0.244 \\
& IT_preference & 0.341 & 0.091 & 0.613 & 3.728 & 0.000 \\
& Peers_influence & 0.163 & 0.038 & 0.369 & 4.294 & 0.000 \\
\hline
\end{tabular}


course of IS. Both these predictors have an absolute $t$-test value of greater than one (large) and their corresponding $p$-values are very small (less than 0.05). Among the significant predictors 'IT preference' and 'peers' influence' indicated a positive relationship (SC $(\beta)=0.613, p=0.0001$ and $\mathrm{SC}(\beta)=0.369, p=$ 0.0001 , respectively), while 'Perceived value of topics' and 'Previous IT knowledge' revealed an inverse relationship $(\mathrm{SC}(\beta)=-0.118, p=0.553$ and $\mathrm{SC}(\beta)=$ $-0.233, p=0.059$, respectively). 'Perceived value for professional practice' was not a significant predictor in this model. In general, a large absolute $t$ value and a small $p$ value suggest that an independent variable is having a large impact on the dependent variable.

The output for the regression analysis is shown in Table 7

Table 7: Regression analysis output: model summary

\begin{tabular}{|c|c|c|c|c|}
\hline Model & $R$ & $R^{2}$ & Adjusted $R^{2}$ & Std. error \\
\hline 1 & $0.860^{1}$ & 0.740 & 0.719 & 0.25353 \\
\hline
\end{tabular}

Previous_IT_knowledge, Perceived_value_of_topics, Professional_practice

The adjusted $R$-squared value takes into account the number of values in the model and the number of participants that the model is based on. We therefore considered the adjusted $R$-squared which gives the most useful measure for the success of the model of multiple regression which indicates that approximately $72 \%$ (0.719) of the dependent variable, perceived relevance of introductory IS course, can be explained by the five independent (predictor) variables.

From the analysis, the main question was answered and the result is positive (67\%); according to student perceptions, ISTN101 should be made compulsory for all business students regardless of their majors. However, only two of the variables appear to have a significant impact on the perceived relevance of the introductory IS course. The strongest factor that contributes to students' attitudes towards IS appears to be their preference for it.

We needed to determine the modes of delivery that students valued most. The course consisted of lectures, tutorials and practical work. In addition to considering students' views of the subject matter, we determined students' views regarding the importance or usefulness of lectures, tutorials and practical work in their overall understanding of IS principles and skills. Students rated lectures, tutorials and laboratory sessions in response to How beneficial were the lectures, tutorials and laboratory sessions to your understanding and learning of the subject matter? Point values for the responses were assigned as follows:

1. not beneficial,

2. of little benefit,

3. fairly beneficial,

4. beneficial,

5. very beneficial.

Means and standard deviations were calculated for each type of learning. Table 8 presents the participants perceived effectiveness of the instructional modes.

Table 8: Benefits of instructional modes

\begin{tabular}{|l|c|c|c|}
\hline Structure & Count & Mean & Std Deviation \\
\hline Lectures & 67 & 2.328358 & 1.235682 \\
Tutorials & 67 & 2.746269 & 1.341 \\
Practicals & 67 & 3.671642 & 1.283792 \\
\hline
\end{tabular}

It would appear that students found practical work most beneficial to their overall understanding. The mean of 3.67 certainly gives an indication of the value students placed on hands-on learning. A clear majority $(65 \%)$ agreed that practical work was most beneficial to their learning, signifying the relevance of what they were doing. Lectures appeared to have been rated as the least beneficial, highlighting the negative view of the theoretical aspects of the course. This finding affirms the positive influence of peers and lecturers for practical work (see Table 5). Thus knowing how to apply theory to practice would certainly assist in establishing relevance of introductory IS courses.

\section{CONCLUSION}

This study explored the perceptions of non-IS majors at a South African university regarding the relevance of the IS introductory course as it relates to their majors and careers. The study employed the Theory of Reasoned Action (TRA) as a framework to determine the factors that impact students' perceptions of the relevance of the introductory IS course. The resulting data gathered proved useful in showing that while many factors independently positively affected their perceptions ('perceived relevance') of the IS introductory course, together they have less impact. It was found using regression analysis that the main two predictors-'IT preference' and 'peers' influence'-significantly impacted one's behavioural intention ('perceived relevance of IS') to have the introductory IS course as a requirement for all business students and perhaps could influence students to switch to IS majors.

The results have implications for practice. The findings of this study can be incorporated into future decision-making regarding curriculum changes to enhance interest and thereby enrolment. Faculty should therefore use the students' perceptions in a number of different ways to interest indecisive students to major in IS, as well as students who may wish to switch majors. Specifically, to grow IS majors, IS departments may want to focus on the value of IS and develop some form of IT drive to enhance their importance and relevance. Understanding non-major IS students' perceptions ('perceived relevance') which influence decisions to major in a certain business area is important for both students and the discipline. This is especially crucial for IS disciplines that wish to boost enrolment, since other business disciplines are the strongest contenders in the number of majors they offer.

Furthermore, relevance of introductory IS courses could be proven by: 
- showing how theory can be applied in practice [22, which affirms the importance of practical work,

- showing relevance to specific situations,

- relating material to everyday applications, or

- finding applications in contemporary situations.

This aspect is affirmed by the overwhelming support for practical ('hands-on') work, as has been shown in the results section. Usually introductory curriculums include a considerable amount of necessary theory, which could deter students if they are unable to see how it applies to the discipline or profession. One of the ways to overcome this drawback could be to show a curriculum map indicating not only the links to more advanced courses of IS, but also as it applies to other courses in the degree.

There is no doubt that managers and administrators simply cannot perform efficiently without a sound understanding of IS in organizations and society.

\subsection{Future research}

The significance of this study and its results may assist ISTN academics at the university and possibly other educational institutions in designing curricula for future introductory IS modules. The research was limited to the students at the university who do not major in ISTN but have done ISTN101. This can be investigated more broadly among other Universities to see if the results differ or if the generalization holds true.

\section{REFERENCES}

[1] J. Freedman and G. Wyner. "Desperately Seeking IS Curriculum Relevance: Teaching Information Systems in a Cross-Functional Context". AMCIS 2012 Proceedings, Paper 24, 2012.

[2] J. Downey, R. McGaughey and D. Roach. "Attitudes and influences toward choosing a business major: The case of information systems". Journal of Information Technology Education: Research, vol. 10, no. 1, pp. 231-251, 2011.

[3] K. A. Walstrom, T. P. Schambach, K. T. Jones and W. J. Crampton. "Why Are Students Not Majoring in Information Systems?." Journal of Information Systems Education, vol. 19, no. 1, pp. 43-54, 2008.

[4] J. T. Gorgone, G. B. Davis, J. S. Valacich, H. Topi, D. L. Feinstein and H. E. Longenecker Jr. "Model curriculum and guidelines for undergraduate degree programs in information systems". Association for Computing Machinery (ACM), Association for Information Systems (AIS), Association of Information Technology Professionals (AITP), 2002.

[5] W. Zhang. "Why IS: Understanding Undergraduate Students' Intentions to Choose an Information Systems Major." Journal of Information Systems Education, vol. 18, no. 4, pp. 447-458, 2007.

[6] C. V. Bullen, T. Abraham, K. Gallagher, J. C. Simon and P. Zwieg. "IT workforce trends: Implications for curriculum and hiring". Communications of the association for information systems, vol. 24, no. 9, pp. 129-140, 2009.
[7] J. F. George, J. S. Valacich and J. Valor. "Does information systems still matter? Lessons for a maturing discipline". Communications of the association for information systems, vol. 16, no. 1, pp. 219-232, 2005.

[8] M. J. Granger, G. Dick, J. Luftman, C. Van Slyke and R. T. Watson. "Information systems enrollments: Can they be increased?" Communications of the Association for Information Systems, vol. 20, no. 1, 2007.

[9] D. Firth, C. Lawrence and C. A. Looney. "Addressing the IS enrollment crisis: a 12-step program to bring about change through the introductory IS course". Communications of the Association for Information Systems, vol. 23, no. 2, pp. 17-36, 2008.

[10] K. Kaminski, J. Switzer and G. Gloeckner. "Workforce readiness: a study of university students' fluency with information technology". Computers $\& 6$ Education, vol. 53, no. 2, pp. 228-233, 2009.

[11] E. Oz. Management Information Systems. CengageBrain. com, 2008.

[12] J. Baugh. "The Disconnect of the Non-Computer Information Systems Major to the Information Systems Literacy Course". Information Systems Education Journal, vol. 5, no. 18, 2007.

[13] P. Sasvári. The Impact Of Information Technology On Business Productivity: Revealing The Link Between Company Size Categories And The Proliferation Of Business Information Systems In Hungary. LAP Lambert Academic Publishing, Saarbrücken, Germany, 2012 .

[14] V. Makrakis. "Perceived relevance of information technology courses to prospective teachers' professional needs: the case of greece". Journal of Information Technology for Teacher Education, vol. 6, no. 2, pp. 157-167, 1997.

[15] B. D. Medlin, S. Schneberger and D. S. Hunsinger. "Perceived technical information technology skill demands versus advertised skill demands: An empirical study". Journal of Information Technology Management, vol. 18, no. 3-4, pp. 14-23, 2007.

[16] T. N. Janicki, T. Lenox, R. Logan and C. R. Woratschek. "Information systems/technology employer needs survey: Analysis by curriculum topic". Information Systems Education Journal, vol. 6, p. 18, 2008.

[17] U. G. Gupta and L. E. Houtz. "High school students' perceptions of information technology skills and careers". Journal of Industrial Technology, vol. 16, no. 4, pp. 2-8, 2000 .

[18] I. Ajzen and M. Fishbein. Understanding attitudes and predicting social behavior. Englewood Cliffs: PrenticeHall, 1980.

[19] F. D. Davis, R. P. Bagozzi and P. R. Warshaw. "User acceptance of computer technology: a comparison of two theoretical models". Management science, vol. 35, no. 8, pp. 982-1003, 1989.

[20] J. W. Creswell. Research Design: Qualitative, Quantitative, and Mixed Methods Approaches. SAGE, Beverley Hills, CA, 2nd ed. edn., 2003.

[21] U. Sekaran and R. Bougie. Research methods for business: A skill building approach. Wiley. com, 2006. 
[22] D. Kember, A. Ho and C. Hong. "The importance of establishing relevance in motivating student learning". active learning in higher education, vol. 9, no. 3, pp. 249-263, 2008. 